\title{
Avoidance of Collision using Copy Cat Technology
}

\author{
Maha Lakshmi. T, Yamini. P, Mahesh Kumar. T
}

\begin{abstract}
The project aims to design an android interface Bluetooth controlled robotic car with master-slave configuration involved in it. Robotic car contains arduino microcontroller with basic mobility features. Arduino programs contain instructions mediating between Android controller and Robotic car. An appropriate program in the arduino microprocessor to interact with the android controller has been created. The program has been successfully complied through arduino IDE to the arduino microprocessor \& loaded into it after proper checking of logic to decrease any loss/damage of hardware. An android application that would provide a user interface to interact with the arduino powered robotic car was created. This interface is easy to use and provide feedback from the arduino microprocessor through the Bluetooth after giving instruction to arduino for various actions via Bluetooth module. The android application is created with the help of android studio that provides more capability \& stability. This project also describes the robots that are configured in master slave technology. In this case the user sends the data from the android device which is received and executed by the master robot and simultaneously the data is broadcasted to the slave robots through the $R F$ transmitter. Slave robots receive the data from the $R F$ receiver, decode it and send the command to Arduino and from then to the motors. Also, there is a provision that any of the robots shall be made the master of the remaining robots. Under any dangerous circumstances (Ex: when the driver is asleep while driving) slave robot uses the path which is followed by master as a navigation and moves in that particular direction. By this technology one shall reduce the number of accidents which leads to decrease of death rate.
\end{abstract}

Keywords: Arduino, Master Slave, Motor Driver, RF module

\section{INTRODUCTION}

Avoidance of collision is based on android application. The main motto is to control the car with android mobile phone instead of any other method like buttons, gesture etc. Here we use mainly Arduino UNO (ATMEGA 328P), Bluetooth module (HC-05). We interface the Bluetooth module with the system so that we can easily control the system by smart phone application. So here android phone is used as transmitting device and Bluetooth module placed in car is used as receiver. This type of robot is more necessary to the modern society in context of spying and surveillance. The controlling of the Robot is done wirelessly through Android smart phone using the Bluetooth feature present in it.

Revised Manuscript Received on April 18, 2020.

* Correspondence Author

Mrs. T. Mahalakshmi*, Assistant Professor in the Department of Electronics and Communication Engineering, Prasad V. Potluri Institute of Technology, Kanuru.

P. Yamini, Bachelor in Electronics and Communication Engineering, Prasad V. Potluri Institute of Technology, Kanuru.

T. Mahesh kumar, Bachelor in Electronics and Communication Engineering, Prasad V. Potluri Institute of Technology, Kanuru

(c) The Authors. Published by Blue Eyes Intelligence Engineering and Sciences Publication (BEIESP). This is an open access article under the CC BY-NC-ND license (http://creativecommons.org/licenses/by-nc-nd/4.0/)
Here in the project the Android smart phone is used as a remote control for operating the Robot so that it so that it can move in the required direction like moving forward, reverse, turning left, turning right and stop. The controlling device of the whole system is a Microcontroller. Bluetooth module, DC motors are interfaced to the Microcontroller. The data received by the Bluetooth module from Android smart phone is fed as input to the controller. The controller acts accordingly on the DC motors of the Robot. The main additional feature of this project is, this autonomous robotic car is configured with master-slave (Copycat) technology which follows the principle of navigation. In this system, there will be a controller (a master device) which will control the other devices (slave robots) while executing the instructions received from an android phone which is used as transmitting device and number of slave devices who will follow the master. In this application, we are using an Android mobile phone as a controller. The commands given by the master doesn't fall into any limitations which abide the slave to perform the action mentioned in the form of an instruction which is transmitted by the master. Thus, only the master is needed to be controlled and then, master will control the slaves. Then, the slaves will perform the same task in real time as that of the master. A command is encoded by the master robot which later is decoded by each slave robot. Motors connected to each robot react according to the inputs given to their motor driver circuits. Any robot can be made as master when it is necessary and remaining robots will act as slaves. This project is cost-effective automation system, which will be easy to implement and which is more required to this modern society. This copycat technology reduces the accidents mainly on high ways.

\section{BACKGROUND}

\section{A. Bluetooth controlled car:}

Bluetooth robotic car is controlled by using android mobile phone [1]. Author [1] says that touch button in phone to control the car in forward, backward, left and right directions. Android phone is used as transmitting device and Bluetooth module placed in the car is used as the receiver in the implementation process.

\section{B. Copycat technology}

The system which includes copycat technology will have a controller device (master device) which will control the other devices (slaves) while executing the instructions received from an android device [2]. The command given by the master does not fall into any limitations which abide the slave to perform the action mentioned in the form of instruction which is transmitted by the master. Command is encoded by the master robot which later is decoded by each slave robots, motors connected to each robot react according to the inputs given to their motor driver circuit [2].

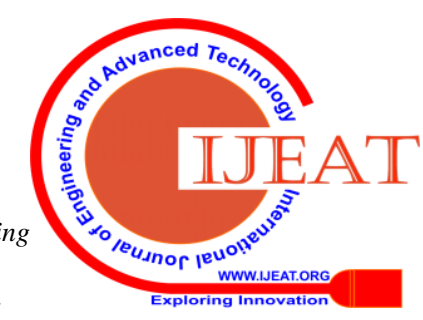




\section{PROPOSED SYSTEM}

Bluetooth controlled car, master-slave technology, and Automatic emergency braking system all these three techniques are separately until now. This paper describes implementation and working of a Bluetooth robotic car with copycat technology along with automatic braking system. Bluetooth car alone can't save from the sudden accidents. In the same manner Car with ABS technology can't be controlled by using android phone.

Master- Slave technology includes the copycat technology in which slaves follows the same path that is instructed by the master robot. The main aim of this project is to build a Bluetooth controlled robot with copycat technology having ABS technique in it. So, this car can be controlled by Bluetooth which acts as a master for the remaining robots and stops its movement immediately whenever the obstacle comes by applying the brake automatically, when the user fails to apply the brake manually. By this we can reduce the number of accidents which leads to decrease in the death rate.

\section{A. Working and implementation of proposed system}

A signal is send to the Bluetooth module by using an android device which has a specified app installed in it. The data received by the Bluetooth module is send to the arduino then the arduino send the data to both motor driver and RF transmitter. The motor driver rotates the wheels as per the given data. The RF transmitter will transmit the data through antenna

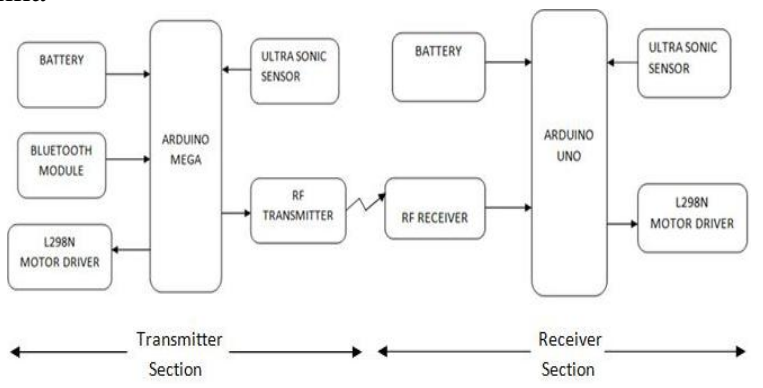

Fig 1. Block diagram of avoidance of collision using copycat technology

present in it. The RF receiver modules receive the data transmitted by the RF transmitter and sends to the arduino. The arduino receive the data and transmit to the motor driver connected to it, than the motor driver rotate the wheels according to the given instructions. Finally this operation takes place in few seconds such that the both robotic cars move simultaneously.

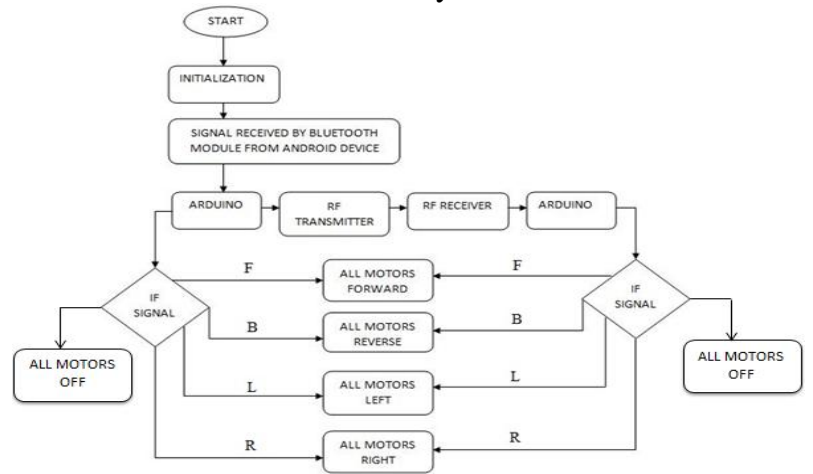

Fig 2. Flowchart of avoidance of collision using copycat technology
By using this technology we can follow the instructions of the car which we have been connected. Not only in four directions, can we also go in any direction. While connected to car we have to make sure that we have active and good connection. Also the RF module should be in good condition.

\section{RESULT}

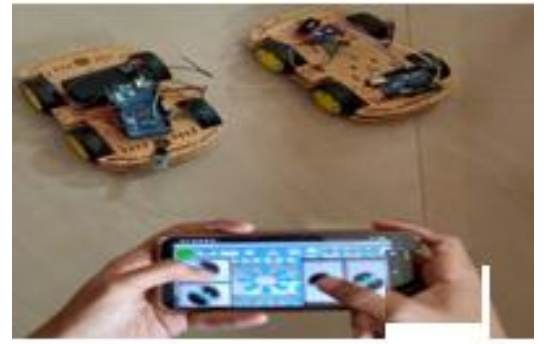

Fig 3. Left movement of robot when master is Commanded to move in left direction

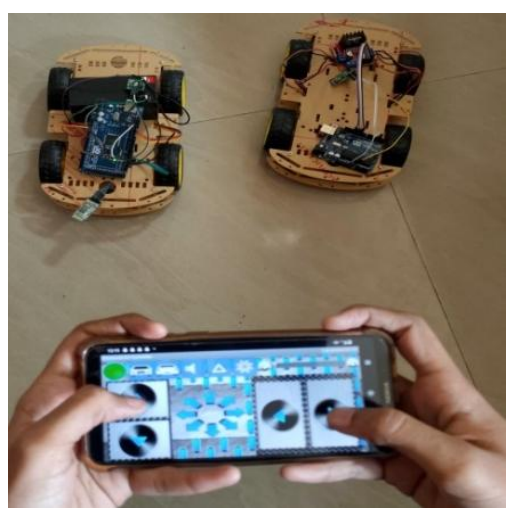

Fig 4. Right movement of robot when master is Commanded to move in right

\section{Explanation of master and slave:}

Power supply is given to the Arduino, Bluetooth module, the RF module [6] and the motor driver in the master robot. Power supply is given to the RF receiver module and motor driver in slave robot. The remote used here is android mobile phone. The mobile phone is used to give commands to the master. The mobile phone is connected to Arduino via Bluetooth module. The Bluetooth module is used because of the security and better communication. Bluetooth requires pairing and hence it is controllable by the person who is desired to control it. With the help mobile phone the Master Robot will be assigned with certain tasks. These instructions given through mobile phone will be executed by the Master Robot. Further, after execution, the same commands will be send to the Slave Robot. The data from Arduino is given to the motor driver. The motor driver drives the motor accordingly.

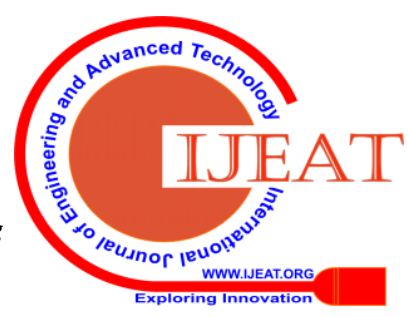




\section{FUTURE SCOPE:}

- Advancements made in the Bluetooth will increase the range of communication.

- By connecting a camera, live images can be seen at the same time.

- Interconnection of many PCs to one by the help of Copycat technology.

\section{CONCLUSION:}

Bluetooth robotic car has been built successfully and is able to move forward, backward, turn left and right properly. The execution of the master and all the slaves is at the same time, hence they are synchronous. Use of Bluetooth brings the security to the whole system. Implementation of Automatic braking system is intended to use in the vehicles where the drivers may not apply the brake manually, but the speed of the vehicle can be reduced automatically due to sensing of obstacles. This is indeed a cost-effective and efficient project.

\section{REFERENCES}

1. Bluetooth Controlled Toy Car using Arduino By Saddam. Dec 25,2015.

2. Master-Slave Configuration Based Bluetooth Controlled Robots by Ankit Panvalkar ${ }^{1}$, Shubham Sawant ${ }^{2}$, Varun Gokhale ${ }^{3}$, Rushabh Shah $^{4}$, Dr. T. Rajani Mangala ${ }^{5}$. Vol. 6, Issue 3, March 2017

3. Design and Implementation of Automatic Emergency Braking System by Sandeep Thorat* , SanketThorve, Jaydatta Upase and Agampal Singh Dhupar. 15 March 2016, Special Issue-4 (March 2016)

4. Wayne Tomasi, "Electronic Communication System"

5. L. Thareja\& A. K. Thareja, "Electrical Technology", vol. 2

6. 6.https://www.engineersgarage.com/components/rf-moduletransmitter-receiver/

\section{AUTHORS PROFILE}

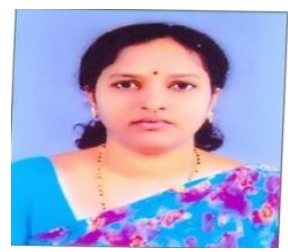

Mrs. T. Mahalakshmi B. Tech degree in 2009,M.Tech in 2011 and now pursuing Ph.D in GITAM Deemed to be University, Visakhapatnam, India. Working as an Assistant Professor in the Department of Electronics and Communication Engineering, Prasad V. Potluri Institute of Technology, Kanuru. The area of interest include Digital Image Processing ,Satellite image and robotics.

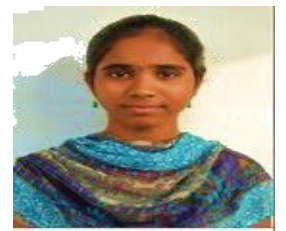

P. Yamini B.Tech degree in 2020. Completed Bachelor in Electronics and Communication Engineering during the academic year 20162020 in Prasad V. Potluri Institute of Technology, Kanuru.

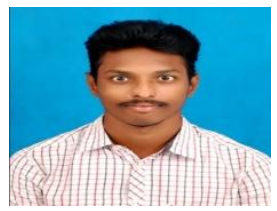

T. Mahesh kumar B.Tech degree in 2020 Completed Bachelor in Electronics and Communication Engineering during the academic year 2016-2020 in Prasad V. Potluri Institute of Technology, Kanuru.

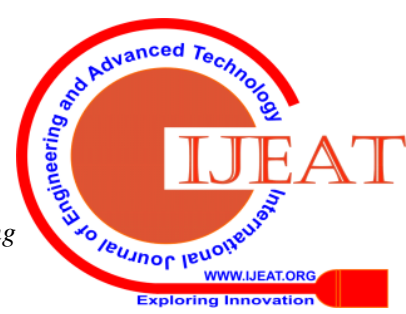

